\title{
Nanotheranostics
}

2018; 2(3): 280-294. doi: 10.7150/ntno.25555

Research Paper

\section{HAase-sensitive dual-targeting irinotecan liposomes enhance the therapeutic efficacy of lung cancer in animals}

\author{
Liang Zhang ${ }^{\bowtie}$, Haixin Cui ${ }^{\bowtie}$ \\ Institute of Environment and Sustainable Development in Agriculture, Chinese Academy of Agricultural Sciences, Beijing, China \\ Nanobiotechnology Research Center, Chinese Academy of Agricultural Sciences, Beijing, China \\ $\triangle$ Corresponding authors: Liang Zhang, PhD, Professor of Pharmaceutics. Tel.: +8610 82107045; E-mail: zhangliang02@caas.cn and Haixin Cui, PhD, Professor \\ of Nanotechnology. Tel.: +8610 82106013; E-mail: cuihaixin@caas.cn \\ (C) Ivyspring International Publisher. This is an open access article distributed under the terms of the Creative Commons Attribution (CC BY-NC) license \\ (https://creativecommons.org/licenses/by-nc/4.0/). See http://ivyspring.com/terms for full terms and conditions.
}

Received: 2018.02.21; Accepted: 2018.05.27; Published: 2018.06.20

\begin{abstract}
Among all cancers, lung cancer is one of the most common and serious types of cancer. It is challenging for site-specific delivery of anticancer therapeutics to tumor cells. Herein, we developed a novel "smart" dual-targeting liposomal platform to respond to the highly expressed hyaluronidase (HAase) in the tumor microenvironment and improve tumor targeting and antitumor efficacy.

Methods: In our design, the HA was used as a sensitive linker between a liposomal lipid and long chain PEG block to synthesize three functional conjugates in order to prepare "smart" liposomal platform modified with epidermal growth factor receptor (EGFR) antibody (GEII) and cell-penetrating peptide (TATp). Using irinotecan as a model therapeutic, evaluations were performed on the human lung adenocarcinoma A549 cells as well as the xenografted A549 cancer cells in nude mice.

Results: The GE11/HA/TATp-irinotecan liposomes evidently increased the uptake of irinotecan and showed significant antitumor efficacy in the xenografted A549 cancer cells in nude mice by intravenous administration. The mechanisms were defined to be two aspects: GE11 exhibits high affinity for EGFR binding and the degradation of the HA by HAase results in the long-chain PEG removal and exposure of the previously hidden surface-attached TATp to enhance the target cell internalization.

Conclusion: Our findings suggest that this functional liposomal platform may provide a novel strategy for treating lung cancers because of effective intracellular delivery.

Key words: Lung cancer; Hyaluronic acid (HA); HAase-sensitive dual-targeting irinotecan liposomes; Antitumor efficiency; Intracellular delivery
\end{abstract}

\section{Introduction}

Lung cancer is the leading cause of cancer-related death in worldwide. The survival rate of this cancer is much less than the other prevalent cancers[1]. Although chemotherapy is the first-line treatment of choice in clinical practice, it achieved limited success with low tumor targeting, insufficient local drug concentration or cellular drug uptake and serious side effects[2].

To address this dilemma, many efforts have been made to improve delivery of chemotherapeutics to tumors, such as liposomes, micelle, dendrimer, polymer and inorganic nanoparticles. Compared with other nanocarriers, liposomes have been clinically approved for cancer treatment because of their capacity of a large payload, the protective bilayers shielding the enclosed therapeutic agents from interaction with the contents of the blood stream, pharmaceutical grade lipids being commercially available and large-scale manufacture being easy to achieve[3,4]. By coating the liposomal surface with PEG-polymers, the circulation time of liposomes can be significantly prolonged and thus their preference 
for tumor accumulation can be achieved because of the enhanced permeability and retention(EPR) effect. However, the selectivity based upon the EPR effect has been demonstrated to vary significantly due to the heterogeneous nature of tumors. Thus, functionalization of liposomes with tumor-specific targeting moieties will be essential to achieve enhanced tumor selectivity[5,6].

Modification of targeting ligands on the surface of liposomes that specifically bind to the receptors can enable liposomes to recognize tumor cells after reaching the tumor region, which is becoming an important strategy in the treatment of cancer. Over expression of epidermal growth factor receptor (EGFR) has been found in human lung adenocarcinoma (A549) cell line. GE11 is a peptide with terminal cysteine (Cys-YHWYGYTPQNVI) and exhibits high affinity for EGFR-positive tumor cells. Therefore, GE11-modified nanocarrier may be a promising candidate for targeted delivery of antitumor drugs to cancer cells over expressing EGFR $[7,8]$.

Although functional liposomes have been developed, insufficient tumor cellular internalization remains a challenge. Accumulation of liposomes in the tumor tissue does not necessarily lead to a higher intracellular uptake of drug. To enhance the intracellular uptake, cell-penetrating peptides (TATp) are used to functionalize the liposomes because they are efficient in aiding translocation across the plasma membrane. So far, many strategies have been extensively developed. However, there is still room for further improvement to maximize the efficacy and minimize the side effects[9,10].

We propose here a strategy that the enzymatically degradable hyaluronic acid (HA) is used as a sensitive linker between lipid and long chain PEG block to design a novel multifunctional liposome, which responds to the over expressed hyaluronidase (HAase) at the tumor microenvironment[11]. A specific peptide (GE11) attached to the surface of the liposome provides an additional recognition and binding within lung tumors (but not with healthy tissues), resulting in tumor cell-specific targeting. When at the tumor microenvironment, the Highly expressed hyaluronidase (HAase) promotes the degradation of the HA, leading to the exposure of TATp and enhanced tumor cellular internalization (Figure 1A and B)[12].

In the present study, we synthesize TATp-polyethylene glycol (1000)-1,2-dioctadecanoylsn-glycero-3-phosphoethanolamine[TATp-PEG(1000) -DSPE] (Scheme 1A), maleimide-polyethylene glycol (2000)-HA-1,2-dioleoyl-snglycero-3-phosphoethanola mine [MAL-PEG(2000)-HA-DOPE] (Scheme 1B) and polyethylene glycol (2000)-HA-1,2-dioleoylsnglycero-3-phosphoethanolamine [PEG(2000)-HADOPE] (Scheme 1C), which are used to prepare HAase-sensitive functional liposomes. Irinotecan is a prodrug and sensitive to A549 cells. Irinotecan is selected as the payload because it can be easily loaded into liposomes with high entrapment efficiency by the $\mathrm{pH}$ gradient method. Onivyde (long-circulating liposomal irinotecan) has recently been approved by the FDA for refractory prostate cancer. GE11 is conjugated to the distal end of MAL-PEG(2000)-HADOPE to prepare the HAase-sensitive dual-targeting irinotecan liposomes.

The objectives of the present study are to prepare and characterize the HAase-sensitive dual-targeting irinotecan liposomes, to assess cellular uptake of the liposomes by fluorescence microscopy, to evaluate the therapeutic efficacy in treating lung cancer and to assess preliminary safety in animals.

\section{Materials and Methods}

\section{Synthesis of TATp-PEG(1000)-DSPE, MAL-PEG(2000)-HA-DOPE and PEG(2000)-HA-DOPE}

To synthesize TATp-PEG(1000)-DSPE (Scheme 1A), $5 \mathrm{mg}$ of TATp (Biochem, China) and $8 \mathrm{mg}$ of MAL-PEG(1000)- DSPE (Avanti Polar Lipids, Alabaster, USA) were dissolved in $3.0 \mathrm{~mL}$ of $\mathrm{pH} 7.4$ HEPES buffer. The reaction mixture was stirred at $4^{\circ} \mathrm{C}$ under nitrogen protection overnight. The excess of TATp was removed by Amicon Ultra centrifugal filters (Millipore, Bedford, MA, USA) followed by lyophilization[13].

To synthesize MAL-PEG(2000)-HA-DOPE (Scheme 1B), the MAL-PEG(2000)- $\mathrm{NH}_{2}$ (Avanti Polar Lipids, Alabaster, USA) was dissolved in anhydrous methanol at room temperature. A solution of sodium hyaluronic acid (HA) $\left(\mathrm{MW}=7.4 \times 10^{3} \mathrm{Da}\right.$, Chaska, MN, USA), 1-Ethyl-3-[3-dimethylaminopropyl] carbodiimide hydrochloride (Sigma-Aldrich Corporation, MO, USA) and N-hydroxysuccinimide (Sigma-Aldrich Corporation, MO, USA) were added with $\mathrm{pH}$ 8.5. The mixture (MAL-PEG(2000)$\mathrm{NH}_{2}$ :HA:EDC:NHS, 1:1:20:20, molar ratio) was stirred for $24 \mathrm{~h}$ at room temperature. MAL-PEG(2000)-HA was isolated by Amicon Ultra centrifugal filters (Millipore, Bedford, MA, USA) followed by lyophilization and stored at $-20{ }^{\circ} \mathrm{C}$ until further use (yield: $~ 83-88 \%$ ). The MAL-PEG(2000)-HA and DOPE (NOF Corporation, Japan) were mixed and dissolved in anhydrous methanol at room temperature. A solution of EDC and NHS were added with $\mathrm{pH} 8.5$. The mixture (MAL-PEG(2000)-HA:DOPE:EDC:NHS, 
1:1:20:20, molar ratio) was stirred for $24 \mathrm{~h}$ at room temperature. MAL-PEG(2000)-HA-DOPE was isolated by Amicon Ultra centrifugal filters (Millipore,
Bedford, MA, USA) followed by lyophilization and stored at $-20{ }^{\circ} \mathrm{C}$ until further use (yield: $\sim 80-83 \%$ ) [14].

A
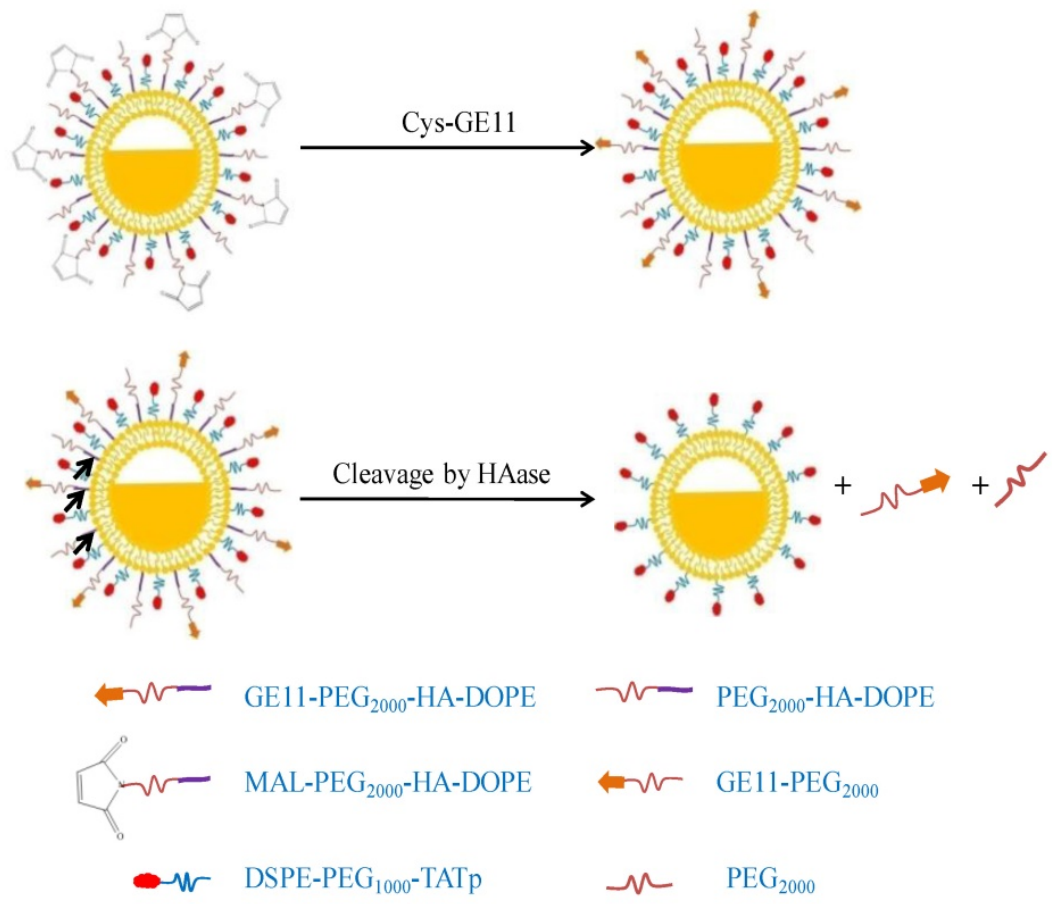

B

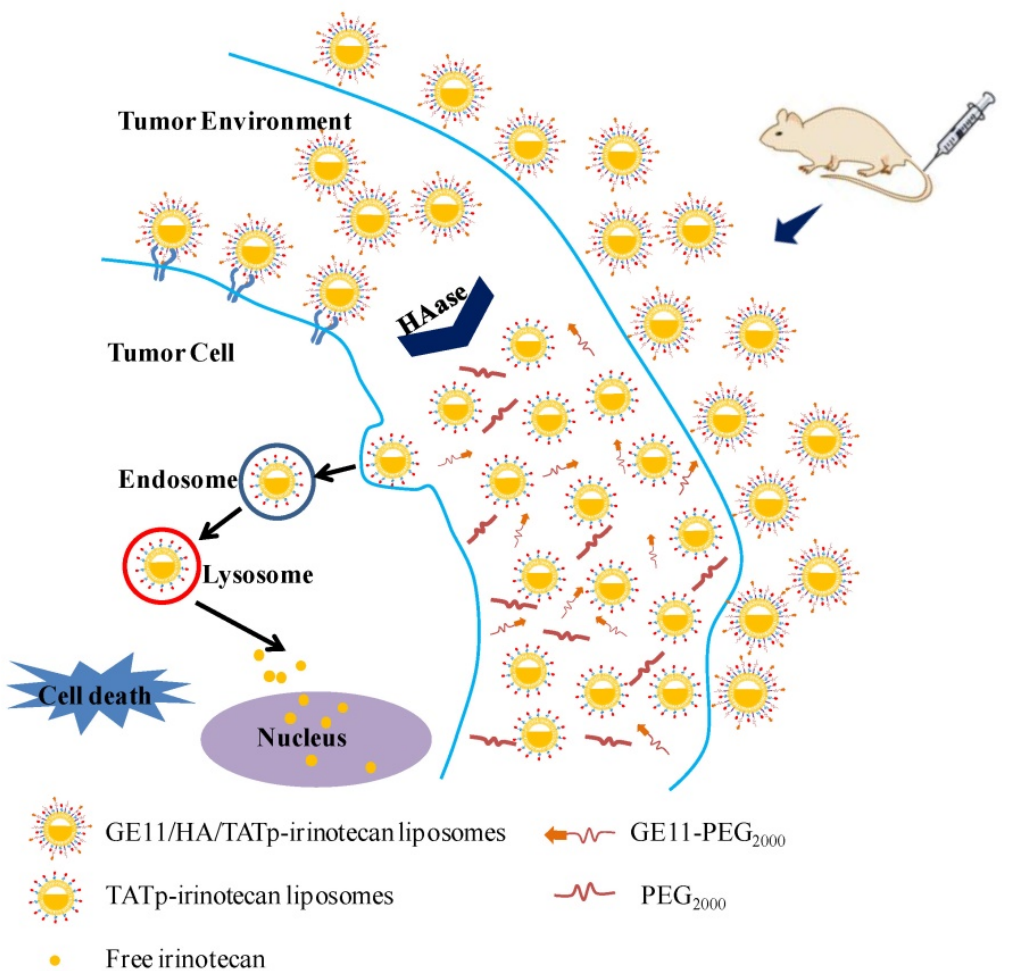

Figure 1. (A) Surface modification of liposomes with GE11 and cleavage by the highly expressed HAase for the removal of PEG chain. (B) Drug delivery strategy of HAase-responsive GE1 1/HA/TATp-irinotecan liposomes. 
A

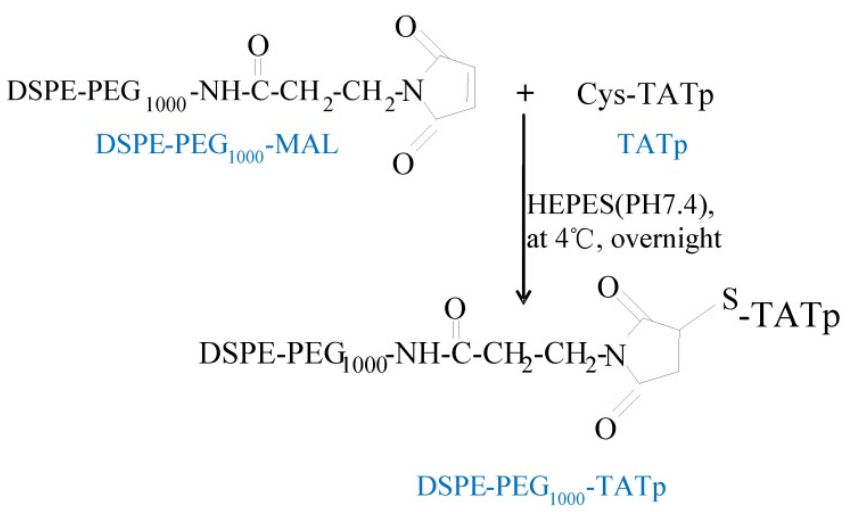

B

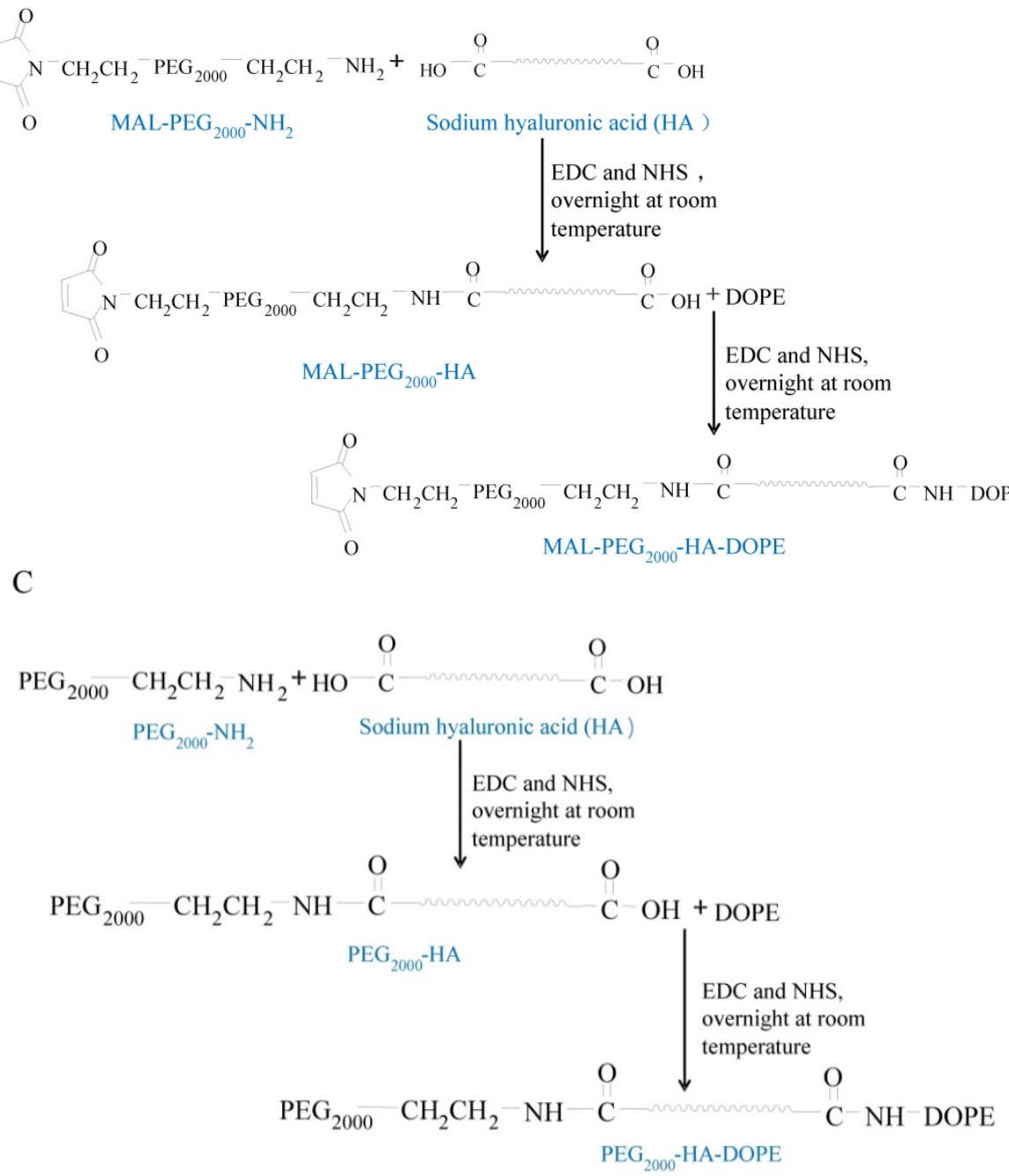

Scheme 1. Synthesis of DSPE-PEG $1000-T A T P(A)$, MAL-PEG $2000-H A-D O P E$ (B), and PEG $2000-H A-D O P E(C)$.

To synthesize PEG(2000)-HA-DOPE (Scheme 1C), the PEG(2000)- $\mathrm{NH}_{2}$ (Avanti Polar Lipids, Alabaster, USA) was dissolved in anhydrous methanol at room temperature. A solution of sodium hyaluronic acid (HA), EDC, and NHS were added with $\mathrm{pH}$ 8.5. The mixture (PEG(2000)$\mathrm{NH}_{2}$ :HA:EDC:NHS, 1:1:20:20, molar ratio) was stirred for $24 \mathrm{~h}$ at room temperature. PEG(2000)-HA was isolated by Amicon Ultra centrifugal filters followed by lyophilization and stored at $-20{ }^{\circ} \mathrm{C}$ until further 
use (yield: 84-89\%). The PEG(2000)-HA and DOPE were mixed and dissolved in anhydrous methanol at room temperature. A solution of EDC and NHS were added with $\mathrm{pH}$ 8.5. The mixture (PEG(2000)HA:DOPE:EDC:NHS, 1:1:20:20, molar ratio) was stirred for $24 \mathrm{~h}$ at room temperature. PEG(2000)HA-DOPE was isolated by Amicon Ultra centrifugal filters followed by lyophilization and stored at $-20^{\circ} \mathrm{C}$ until further use (yield: 81-84\%).

\section{Preparation of liposomes}

To prepare the HAase-sensitive TATp-blank liposomes, the lipid mixture of egg phosphatidylcholine (EPC) (Sigma-Aldrich Corporation, MO, USA), cholesterol (Sigma-Aldrich Corporation, MO, USA), PEG(2000)-HA-DOPE, TATp-PEG(1000)- DSPE and MAL-PEG(2000)-HA-DOPE (55:45:4:1:1 $\mu \mathrm{mol} /$ $\mu \mathrm{mol})$ were dissolved in chloroform in a pear shaped flask. The chloroform was evaporated to dryness under vacuum with a rotary evaporator, and then the formed lipid film was hydrated with $250 \mathrm{mM}$ ammonium sulfate by sonication in the water bath for $5 \mathrm{~min}$, followed by sonication using a probe-type sonicator for $10 \mathrm{~min}$. The suspensions after hydration were successively extruded through polycarbonate membranes (Millipore, Bedford, MA, USA) with the pore size of $400 \mathrm{~nm}, 200 \mathrm{~nm}$, and $100 \mathrm{~nm}$ for 3 times, respectively. Afterwards, the HAase-sensitive TATpblank liposomes were obtained[15].

To prepare the HAase-sensitive TATpirinotecan liposomes, the TATp-blank liposomes were then dialyzed $(8,000-15,000$ molecular mass cutoff) (Beijing Dingguo Biotechnology Limited Company, China) in the $500 \mathrm{ml}$ physiological saline $(0.9 \% \mathrm{NaCl})$ for two times. Irinotecan was loaded using an ammonium sulfate gradient loading method, as reported previously. Appropriate amounts of irinotecan hydrochloride (Jiangsu Henrui Medicine Corporation, China) were added to the TATp-blank liposomes. After mixing, the suspensions were incubated at $50{ }^{\circ} \mathrm{C}$ in water bath, and intermittently shaken for $30 \mathrm{~min}$ to produce the HAase-sensitive TATp-irinotecan liposomes.

To prepare the HAase-sensitive dual-targeting irinotecan, the liposomes were incubated with GE11 (purify: $\sim 99 \%$, Biochem, China) (maleimide group: GE11=1:2, mol: mol). The reaction was carried out in pH 7.4 HEPES-buffered saline (HBS) (50 mM HEPES, $150 \mathrm{mM} \mathrm{NaCl}$ ) containing $10 \mathrm{mM} \mathrm{CaCl}$, containing 4 $\mathrm{mM}$ EDTA at $4{ }^{\circ} \mathrm{C}$ overnight. The liposome suspensions were applied to a quick spin Sephadex G-50 column (Fisher Scientific, Pittsburg, PA) equilibrated with PBS and centrifuged at $150 \mathrm{~g}$ at $4{ }^{\circ} \mathrm{C}$ to remove the uncoupled GE11 antibodies and free irinotecan to produce the HAase-sensitive dual-targeting irinotecan liposomes which are referred to as GE/HA/TATp- irinotecan liposomes[16].

To prepare HAase-sensitive GE11-targeting irinotecan liposomes which are referred to as GE11-irinotecan liposomes, the liposomes were made with the same method, excluding the addition of TATp-PEG(2000)-DSPE during film forming.

To prepare TATp modifying irinotecan liposomes which are referred to as TATp-irinotecan liposomes, the liposomes were made with the same method, excluding the addition of PEG(2000)-HADOPE and MAL-PEG(2000)-HA-DOPE during film forming.

To prepare irinotecan liposomes, the liposomes were made with the same method, excluding the addition of TATp-PEG(2000)-DSPE and MALPEG(2000)-HA-DOPE during film forming.

\section{Measurements}

Irinotecan was analyzed by HPLC with fluorescence detection (Agilent Technologies Inc., Cotati, CA, USA). Irinotecan was separated by a Diamonsil $\mathrm{C}_{18}$ column $(200 \times 4.6 \mathrm{~mm}, 5 \mu \mathrm{m})$. The mobile phase consisted of acetonitrile and water containing $2.1 \%$ citric acid and $0.2 \%$ triethylamine $(40 / 60, \mathrm{v} / \mathrm{v})$ with a flow rate of $1.0 \mathrm{ml} / \mathrm{min}$ under isocratic conditions. $\mathrm{pH}$ was 3.8 settled by $30 \%$ natrium hydroxydatum. The fluorescence detection was set at $\lambda_{\text {ex }} 370 \mathrm{~nm}$ and $\lambda_{\mathrm{em}} 530 \mathrm{~nm}$.

\section{Characterization of GE/HA/TATp-irinotecan liposomes}

The modifying rate of GE11 was calculated with the formula: $\mathrm{MR}=\left(\mathrm{W}_{\text {modifying }} / \mathrm{W}_{\text {total }}\right) \times 100 \%$, where MR is the modifying rate of GE11, $W_{\text {modifying }}$ is the measured amount of GE11 in the liposomes after passing over the column, and $\mathrm{W}_{\text {total }}$ is the measured amount of GE11 in the equal volume of liposomal suspensions before passing over the column. The content of GE11 antibodies on the liposomes was determined by bicinchoninic acid (BCA) assay.

Similarly, the encapsulation efficiency of irinotecan in liposomes was calculated with the formula: $\mathrm{EE}=\left(\mathrm{W}_{\text {encap }} / \mathrm{W}_{\text {total }}\right) \times 100 \%$, where $\mathrm{EE}$ is the encapsulation efficiency of irinotecan, $W_{\text {encap }}$ is the measured amount irinotecan in the liposomal suspensions after passing over the column, and $\mathrm{W}_{\text {total }}$ is the measured amount irinotecan in the equal volume of liposomal suspensions before passing over the column. The irinotecan concentration was determined by HPLC.

In vitro release of irinotecan in the liposomes was performed by the dialysis against the release medium containing serum protein (phosphate 
buffered saline containing $10 \%$ fetal calf serum) for maintaining the $\mathrm{pH}$ at 7.4. For $\mathrm{pH} 6.0$ and 5.0, the release medium was adjusted accordingly with additional hydrochloric acid. A volume of $2.5 \mathrm{ml}$ liposomes plus $2.5 \mathrm{ml}$ of release medium in dialysis tubing was immersed in $30.0 \mathrm{ml}$ of the release medium, and oscillated with a shaker at a rate of 150 times per minute at $37^{\circ} \mathrm{C}$. A volume of $0.5 \mathrm{ml}$ release medium was taken at various time points up to $120 \mathrm{~h}$, and immediately replaced with the same volume of fresh release medium after each sampling. The irinotecan content in the release medium was determined by HPLC as above. The release rate was calculated with the formula: $\mathrm{RR}=(\mathrm{Wi} / \mathrm{Wtotal})$ $\times 100 \%$, where RR is the drug release rate $(\%), \mathrm{Wi}$ is the measured amount of irinotecan at the time-point of ith $\mathrm{h}$ in release medium, and Wtotal is the total amount of irinotecan in the equal volume of liposomal suspensions prior to dialysis[17].

The particle sizes and zeta potential values of all liposomes were measured with Zetasizer 3000HSA (Malvern Instruments Ltd., Malvern, Worcestershire, UK).

\section{Culture of A549 cells}

The culture medium was prepared with DMEM (Macgene Biotech Co., Ltd, Beijing, China) supplemented with $10 \%$ heat-inactivated fetal bovine serum (Invitrogen), 100 units $/ \mathrm{ml}$ penicillin (Sigma-Aldrich Corporation, MO, USA), and 100 units/ml streptomycin ((Sigma-Aldrich Corporation, MO, USA). The cells human lung adenocarcinoma A549were cultured in the incubator at $37^{\circ} \mathrm{C}$ and in the presence of $5 \% \mathrm{CO}_{2}$.

\section{Cytotoxicity to A549 Cells}

A549 cells were seeded into 96-well culture plates at a density of $9.0 \times 10^{3}$ cells per well and grown in culture medium in the incubator at $37^{\circ} \mathrm{C}$ and in the presence of $5 \% \mathrm{CO}_{2}$ for $24 \mathrm{~h}$. Irinotecan liposomes (0-5 $\mu \mathrm{M})$, TATp-irinotecan liposomes $(0-5 \mu \mathrm{M})$, GE11-irinotecan liposomes $(0-5 \quad \mu \mathrm{M})$ and GE11/HA/TATp-irinotecan liposomes $(0-5 \mu \mathrm{M})$ with/without pre-incubation with HAase were added into 96-well culture plates, respectively. The survival rate was measured at $48 \mathrm{~h}$ by the sulforhodamine $\mathrm{B}$ (SRB) staining assay, and the absorbance was read on a microplate reader at $540 \mathrm{~nm}$. The survival percentages were calculated using the following formula: Survival $\%=\left(\mathrm{A}_{540 \mathrm{~nm}}\right.$ for the treated cells $/ A_{540 \mathrm{~nm}}$ for the control cells) $\times 100 \%$, where $\mathrm{A}_{540 \mathrm{~nm}}$ is the absorbance value. Each assay was repeated in triplicate. Finally, the dose-effect curves were plotted[18].

\section{Flow Cytometry Studies}

Approximately $6 \times 10^{5}$ A549 cells per well were seeded in a 6-well plate $24 \mathrm{~h}$ prior to study, and cells were incubated at $37{ }^{\circ} \mathrm{C}$ for $1 \mathrm{~h}$ with irinotecan liposomes $(1.5 \mu \mathrm{M})$, TATp-irinotecan liposomes (1.5 $\mu \mathrm{M})$, GE11-irinotecan liposomes $(1.5 \mu \mathrm{M})$ and GE11/HA/TATp-irinotecan liposomes $(1.5 \mu \mathrm{M})$ with/without pre-incubation with HAase. Then, cells were trypsinized, pelleted by centrifugation, washed three times with cold PBS and finally examined by a flow cytometer (FACScan, Becton Dickinson, San Jose, CA), excited at $488 \mathrm{~nm}$ and detected at $560 \mathrm{~nm}$. Data were analyzed with the FACStation software.

\section{Intracellular uptake of GE/HA/TATp-irinotecan liposomes}

Intracellular uptake of GE/HA/TATp-irinotecan liposomes was determined by fluorescence microscope. A549 cells were maintained in Dulbecco modified Eagle medium (DMEM) supplemented with $10 \%$ FBS and were seeded onto six well plates at $3.0 \times$ $10^{5}$ per well and cultured for $24 \mathrm{~h}$ at $37^{\circ} \mathrm{C}$ and in the presence of $5 \% \mathrm{CO}_{2}$, followed by adding irinotecan liposomes $(1.5 \mu \mathrm{M})$, TATp-irinotecan liposomes (1.5 $\mu \mathrm{M})$, GE11-irinotecan liposomes $(1.5 \mu \mathrm{M})$ and GE11/HA/TATp-irinotecan liposomes $(1.5 \mu \mathrm{M})$ with/without pre-incubation with HAase. Phosphate buffered saline (PBS, pH7.4) was added as a blank control. After $10 \mathrm{~min}$ incubation, the medium was removed and the cells were washed away with PBS three times. Then, the cells were fixed with $4 \%$ paraformaldehyde (PFA). Irinotecan signals were captured under fluorescence microscope and merged with the immunocytochemical staining of nuclei with Dapi[19].

\section{Xenograft tumor animal models}

Female BALB/c nude mice (18-20g) were housed under specific pathogen-free conditions. Animals possessed continuous access to sterilized food pellets and distilled water. All animal procedures were approved by the Institutional Animal Care and Use Committee. A549 cells $\left(3 \times 10^{6}\right)$ in $100 \mu \mathrm{l}$ of serum-free medium containing $25 \%$ Matrigel (BD Biosciences, San Jose, CA) were injected subcutaneously on a thigh of anesthetized mice.

\section{In vivo inhibition of the tumor growth and effects on the indicators of bone marrow}

When tumors reached $150 \mathrm{~mm}^{3}$ in volume, mice were randomly divided into six treatment groups (6 for each group). At day 11, 15, 19, and 23 post inoculation, physiological saline (blank control), free irinotecan $(20.00 \mathrm{mg} / \mathrm{kg})$, irinotecan liposomes $(20.00$ $\mathrm{mg} / \mathrm{kg})$, TATp-irinotecan liposomes $(20.00 \mathrm{mg} / \mathrm{kg})$, 
GE11-irinotecan liposomes (20.00 $\mathrm{mg} / \mathrm{kg})$ and GE11/HA/TATp-irinotecan liposomes $(20.00 \mathrm{mg} / \mathrm{kg})$ were given intravenously to mice which had been randomly divided into six treatment groups (6 for each) via tail vein, respectively. The presence of each tumor mass was confirmed by necropsy at day 25 since the inoculation. Mice were weighed and tumors were measured with a caliper every one or every two days. Tumor volumes were calculated with the formula (length $\times$ width $^{2} / 2$ )[20].

At day 25, the mice were sacrificed. The tumors were collected, washed with physiological saline, dried with filter paper, and weighted accurately and stored at $-20^{\circ} \mathrm{C}$. The tumors were homogenized with a homogenizer in physiological saline. A $3.0 \mathrm{ml}$ volume of methanol was added to $100 \mu \mathrm{l}$ tumor homogenate ( $0.15 \mathrm{~g}$ of tissue) and mixed for $3 \mathrm{~min}$ with a vortex, followed by centrifugation at 10,000 rpm for $5 \mathrm{~min}$. The liquid phase was transferred to a clean tube and dried under a gentle $\mathrm{N}_{2}$ gas stream to obtain residues containing the irinotecan. The irinotecan residue was reconstituted with $100 \mu \mathrm{l}$ mobile phase and centrifuged at 10,000 rpm for 5 min. Finally, a $20 \mu \mathrm{l}$ volume of supernatant was injected into the HPLC system. The samples were analyzed by HPLC.

Blood specimens of the mice were collected immediately after sacrifice. The blood specimens were used for measuring the indicators of bone marrow in peripheral blood (white blood cells, WBC; hemoglobin, $\mathrm{Hb}$; platelet, PLT) ${ }^{[20]}$.

\section{Pharmacokinetics}

All animal procedures were approved by the Institutional Animal Care and Use Committee. Female Sprague-Dawley (SD) rats were used for investigating the pharmacokinetics and randomly divided into five groups ( 6 for each group). Free irinotecan $(20.00 \mathrm{mg} / \mathrm{kg})$, irinotecan liposomes $(20.00$ $\mathrm{mg} / \mathrm{kg})$, TATp-irinotecan liposomes $(20.00 \mathrm{mg} / \mathrm{kg})$, GE11-irinotecan liposomes (20.00 $\mathrm{mg} / \mathrm{kg})$ and GE11/HA/TATp-irinotecan liposomes $(20.00 \mathrm{mg} / \mathrm{kg}$ ) were given intravenously to rats via tail vein, respectively. After administrations, a $1 \mathrm{ml}$ volume of plasma was collected in a heparinized microcentrifuge tube from retro orbital sinus at the following time points: $15 \mathrm{~min}, 30 \mathrm{~min}, 1 \mathrm{~h}, 2 \mathrm{~h}, 4 \mathrm{~h}, 8 \mathrm{~h}$, $12 \mathrm{~h}, 24 \mathrm{~h}$ and $48 \mathrm{~h}$. The plasma was separated by centrifugation at 12,000 rpm for $10 \mathrm{~min}$ and stored at $-20^{\circ} \mathrm{C} 2$. A $3.0-\mathrm{ml}$ volume of methanol was added to the $100 \mu \mathrm{l}$ plasma and mixed for 3 min with a vortex, followed by centrifugation at 10,000 rpm for $5 \mathrm{~min}$. The liquid phase was transferred to a clean tube and dried under a gentle $\mathrm{N}_{2}$ gas stream to obtain residues containing the irinotecan. The irinotecan residue was reconstituted with $100 \mu \mathrm{l}$ mobile phase and centrifuged at 10,000 rpm for $5 \mathrm{~min}$. Finally, a $20 \mu \mathrm{l}$ volume of supernatant was injected into the HPLC system.

The samples were analyzed by HPLC with fluorescence detection (Waters Technologies Inc., Cotati, CA, USA). Irinotecan was separated by a Diamonsil $\mathrm{C}_{18}$ column $(200 \times 4.6 \mathrm{~mm}, 5 \mu \mathrm{m})$. The mobile phase consisted of acetonitrile and water containing $2.1 \%$ citric acid and $0.2 \%$ triethylamine $(40 / 60, \mathrm{v} / \mathrm{v})$ with a flow rate of $1.0 \mathrm{ml} / \mathrm{min}$ under isocratic conditions. $\mathrm{pH}$ was 3.8 settled by $30 \%$ natrium hydroxydatum. The fluorescence detection was set at $\lambda$ ex $370 \mathrm{~nm}$ and $\lambda e m 530 \mathrm{~nm}$.

\section{Statistical Analysis}

Data are presented as the mean \pm standard deviation. One-way analysis of variance was used to determine significance among groups, after which post hoc tests with the Bonferroni correction were used for multiple comparisons between individual groups. A value of $\mathrm{p}<0.05$ was considered to be significant.

\section{Results}

\section{Synthesis of TATp-PEG(1000)-DSPE, MAL-PEG(2000)-HA-DOPE and PEG(2000)-HA-DOPE.}

Scheme $1 \mathrm{~A}$ is the synthesis scheme for TATp-PEG-(1000)-DSPE. The sulfhydryl group of cysteine-modified TAT peptide reacted with the maleimide group of maleimide-PEG(1000)-DSPE efficiently at PH 7.4.

Scheme 1B shows the synthesis scheme for MAL-PEG(2000)-HA-DOPE. The MAL-PEG(2000)$\mathrm{NH}_{2}$ and DOPE were activated by the coupling reagents NHS/EDC and reacted with HA via the esterification reaction.

Scheme 1C shows the synthesis scheme for PEG(2000)-HA-DOPE. The PEG(2000)- $\mathrm{NH}_{2}$ and DOPE were activated by the coupling reagents NHS/EDC and reacted with HA via the esterification reaction.

\section{Characterization of liposomes}

Table 1 represents the characterization results of four liposomes. In the liposomes prepared, the modifying rate of GE11 as a targeting molecule was $>95 \%$. The encapsulation efficiency of irinotecan was $>90 \%$. The mean particle sizes of irinotecan liposomes, TATp-irinotecan liposomes, GE11-irinotecan liposomes and GE11/HA/TATp-irinotecan liposomes were $56.23 \pm 2.89,53.12 \pm 2.15,52.66 \pm 2.09$ and $50.98 \pm$ $2.25 \mathrm{~nm}$, respectively. Their corresponding potential values were $-1.27 \pm 0.21,-1.36 \pm 0.18,-1.44 \pm 0.13$ and $-1.56 \pm 0.19 \mathrm{mv}$, respectively. The polydispersity indice 
for all liposomes were $0.126 \pm 0.013,0.129 \pm 0.023$, $0.124 \pm 0.016$ and $0.128 \pm 0.012$, respectively.

Table 1. Characterizations of four irinotecan liposomes
1. Modifying efficiency of GE11

GE11-irinotecan liposomes

GE11/HA/TATp-irinotecan liposomes

2. Encapsulation efficiency of irinotecan

Irinotecan liposomes

TATp-irinotecan liposomes

GE11-irinotecan liposomes

GE11/HA/TATp-irinotecan liposomes

3. Size of irinotecan liposomes

Irinotecan liposomes

TATp-irinotecan liposomes

GE11-irinotecan liposomes

GE11/HA/TATp-irinotecan liposomes

4. Zeta potential of irinotecan liposomes

Irinotecan liposomes

TATp-irinotecan liposomes

GE11-irinotecan liposomes

GE11/HA/TATp-irinotecan liposomes

5. PDI of irinotecan liposomes

Irinotecan liposomes

TATp-irinotecan liposomes

GE11-irinotecan liposomes

GE11/HA/TATp-irinotecan liposomes
Results (\%)

$96.66 \pm 1.31 \%$

$96.92 \pm 1.15 \%$

Results (\%)

$93.33 \pm 2.26 \%$

$94.16 \pm 2.19 \%$

$94.55 \pm 2.61 \%$

$94.72 \pm 2.06 \%$

Results

Mean size $(\mathrm{nm})$

$56.23 \pm 2.89$

$53.12 \pm 2.15$

$52.66 \pm 2.09$

$50.98 \pm 225$

Results

$-1.27 \pm 0.21 \mathrm{mv}$

$-1.36 \pm 0.18 \mathrm{mv}$

$-1.44 \pm 0.13 \mathrm{mv}$

$-1.56 \pm 0.19 \mathrm{mv}$

Results

$0.126 \pm 0.013$

$0.129 \pm 0.023$

$0.124 \pm 0.016$

$0.128 \pm 0.012$
Each point represents means \pm SD $(n=3)$. Note: PDI, Polydispersity index.

Figure 2A shows the release rates of irinotecan from four different liposomes in PBS solution containing $10 \%$ serum protein oscillated at a rate of 150 times per minute at $37^{\circ} \mathrm{C}$. Release rate of irinotecan from the liposomes was negligible within 48 hours. The leakage started to increase slightly after lowering the extra-liposomal $\mathrm{pH}$ to 6.0 and 5.0.

\section{Cytotoxicity to A549 Cells}

Figure 2B shows the inhibitory effects to A549 cells after applying various formulations. As compared to irinotecan liposomes, TATp-irinotecan liposomes, GE11-irinotecan liposomes and GE11/ HA/TATp-irinotecan liposomes, GE11/HA/TATpirinotecan liposomes after HAase pre-treatment showed the strongest inhibitory effects at various dose levels. For example, the rank of survival rates after applying $5 \mu \mathrm{M}$ irinotecan were irinotecan liposomes $(28.87 \pm 1.32 \%)>$ GE11-irinotecan liposomes $(19.19 \pm 1.80 \%)>$ GE11/HA/TATpirinotecan liposomes $(18.33 \pm 1.37 \%)>$ TATp-irinotecan liposomes (15.24 $\pm 1.01 \%) \quad>$ GE11/HA/TATp- irinotecan liposomes after HAase pre-treatment $(8.39 \pm 1.19 \%)$.

\section{Flow Cytometry Studies}

The kinetic uptakes of irinotecan by A549 lung cancer cells at $37^{\circ} \mathrm{C}$ were shown in Figure 3. It was clear that the cell endocytosis of GE11/HA/TATpirinotecan liposomes after HAase pre-treatment was much higher than that of GE11/HA/TATp-irinotecan liposomes, TATp-irinotecan liposomes, GE11-irinotecan liposomes and irinotecan liposomes for cells.

\section{Intracellular uptake of GE1 1/HA/TATp-irinotecan liposomes}

Figure 4 shows the intracellular uptake of GE11/HA/TATp-irinotecan liposomes. After different liposomal formulations were incubated with A549 lung cancer cells. Intracellular irinotecan signals were clearly seen in cells treated with GE11/HA/TATpirinotecan liposomes after HAase pre-treatment only. There were essentially little signal observed after treatment with irinotecan liposomes, GE11-irinotecan liposomes, TATp-irinotecan liposomes and GE11/ HA/TATp-irinotecan liposomes without HAase pre-treatment.

\section{In vivo inhibition of the tumor growth and effects on the indicators of bone marrow}

Figure 5A shows the efficacy of GE11/HA/TATp-irinotecan liposomes in treating the A549 cells xenografts tumor model. After inoculation of A549 cells in female nude mice, the tumors reached suitable masses for treatment. As compared to blank control group, the inhibitory effects of tumor growth were obviously observed in all treatment groups. The rank of inhibitory effects was GE11/HA/ TATp-irinotecan liposomes > GE11-irinotecan liposomes $>$ TATp-irinotecan liposomes $>$ irinotecan liposomes $>$ free irinotecan $>$ the blank control with tumor volume at day 25 . The inhibitory effects were further demonstrated by calculating tumor weights and irinotecan level in tumors, as shown in Figure 5C and $\mathrm{D}$.

Figure 5B shows the body weight changes of the tumor-bearing mice during the study of antitumor efficacy. In view of results observed in all treatment groups, body weight loss was not observed significantly in the mice after giving GE11/HA/TATp-irinotecan liposomes but found in the mice after giving PEG-coated free irinotecan, irinotecan liposomes, TATp-irinotecan liposomes and GE11-irinotecan liposomes.

Figure 6 shows the effects of various formulations on the hematological indicators of bone marrow. After administration of GE11/HA/TATpirinotecan liposomes, the levels of $\mathrm{WBC}, \mathrm{Hb}$, and PLT in blood specimens were slightly decreased, but without significant difference as compared to those in control group. After administration of TATpirinotecan liposomes, GE11-irinotecan liposomes and irinotecan liposomes, the levels of $\mathrm{WBC}, \mathrm{Hb}$, and PLT in blood specimens were decreased. However, the levels of $\mathrm{WBC}, \mathrm{Hb}$, and PLT were severely lowered after administration of free irinotecan. 
A

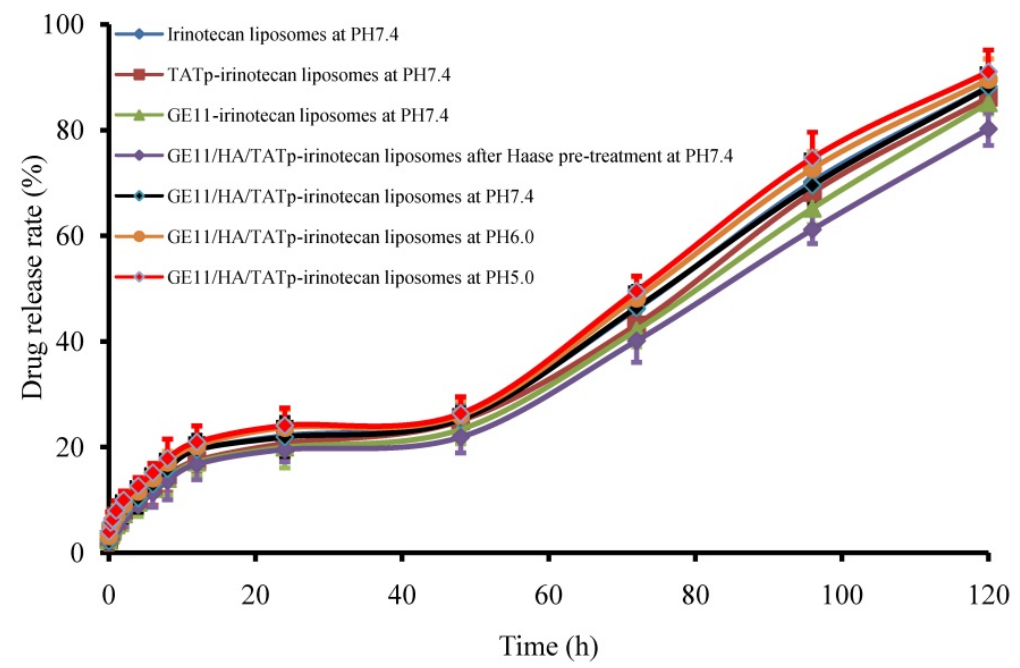

B

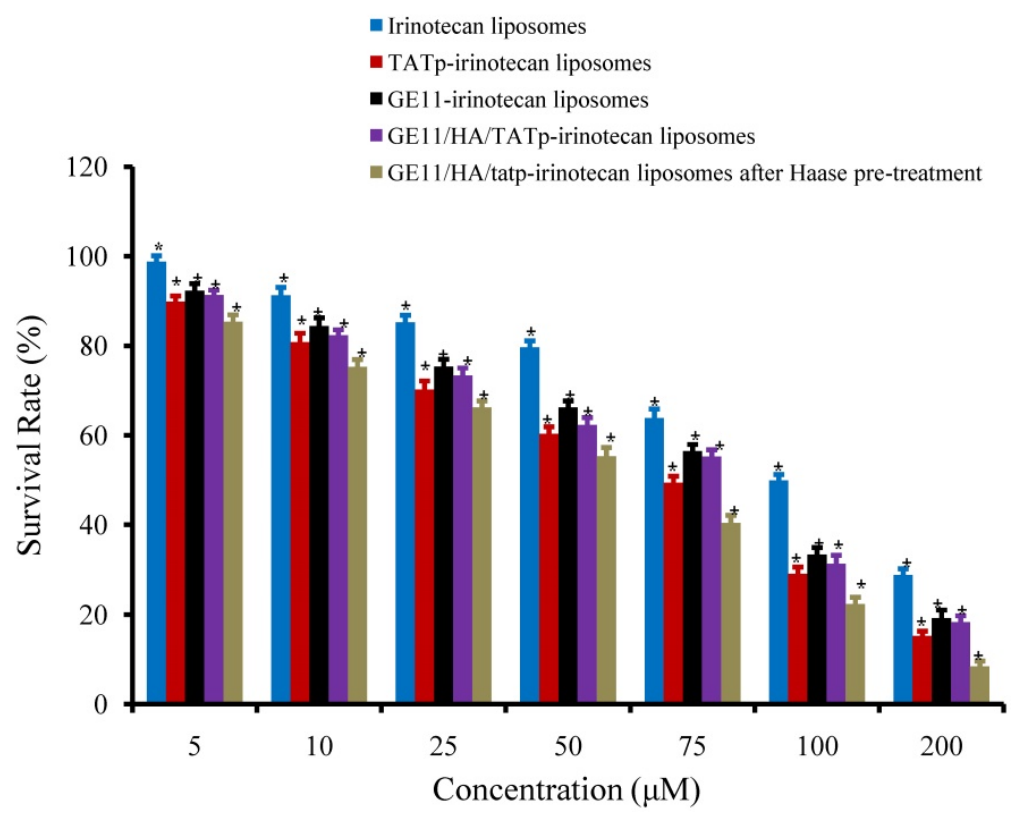

Figure 2. (A)Release rates of irinotecan from liposomal formulations in PBS solution containing $10 \%$ serum protein oscillated with a shaker at a rate of 100 times per minute at $37^{\circ} \mathrm{C}$ respectively. (B) Survival rates of A549 cells after applying various irinotecan formulations measured by SRB staining assay. Data are presented as the mean \pm SD $(n=3)$. An asterisk $(*)$ denotes a significant difference compared with the other groups $(p<0.05)$.

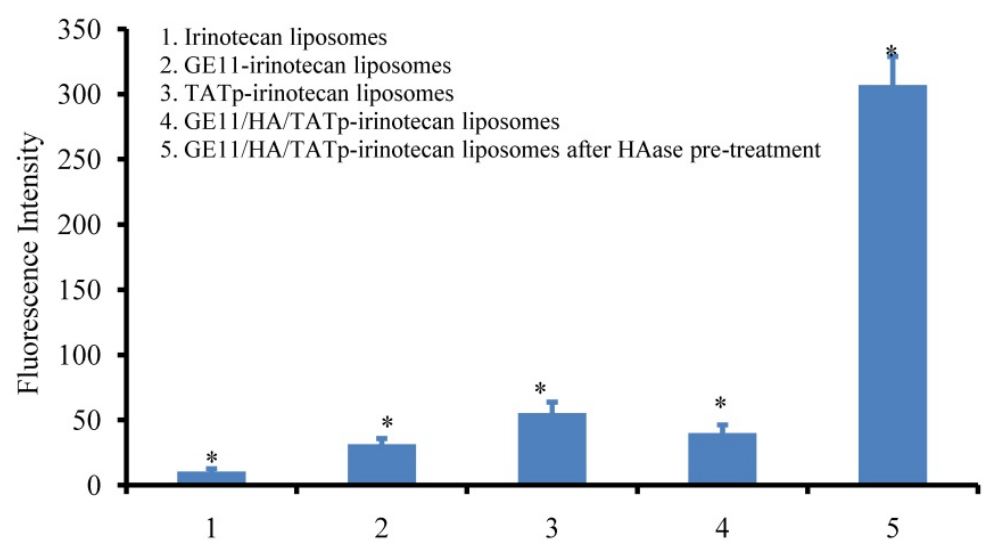

Figure 3. The uptake of $\mathrm{A} 549$ lung cancer cells at $37^{\circ} \mathrm{C}$ following applying various liposomes, monitored by flow cytometry. Each point represents mean fluorescence intensity \pm SD $(n=3)$. An asterisk $(*)$ denotes a significant difference compared with the other groups $(p<0.05)$. 


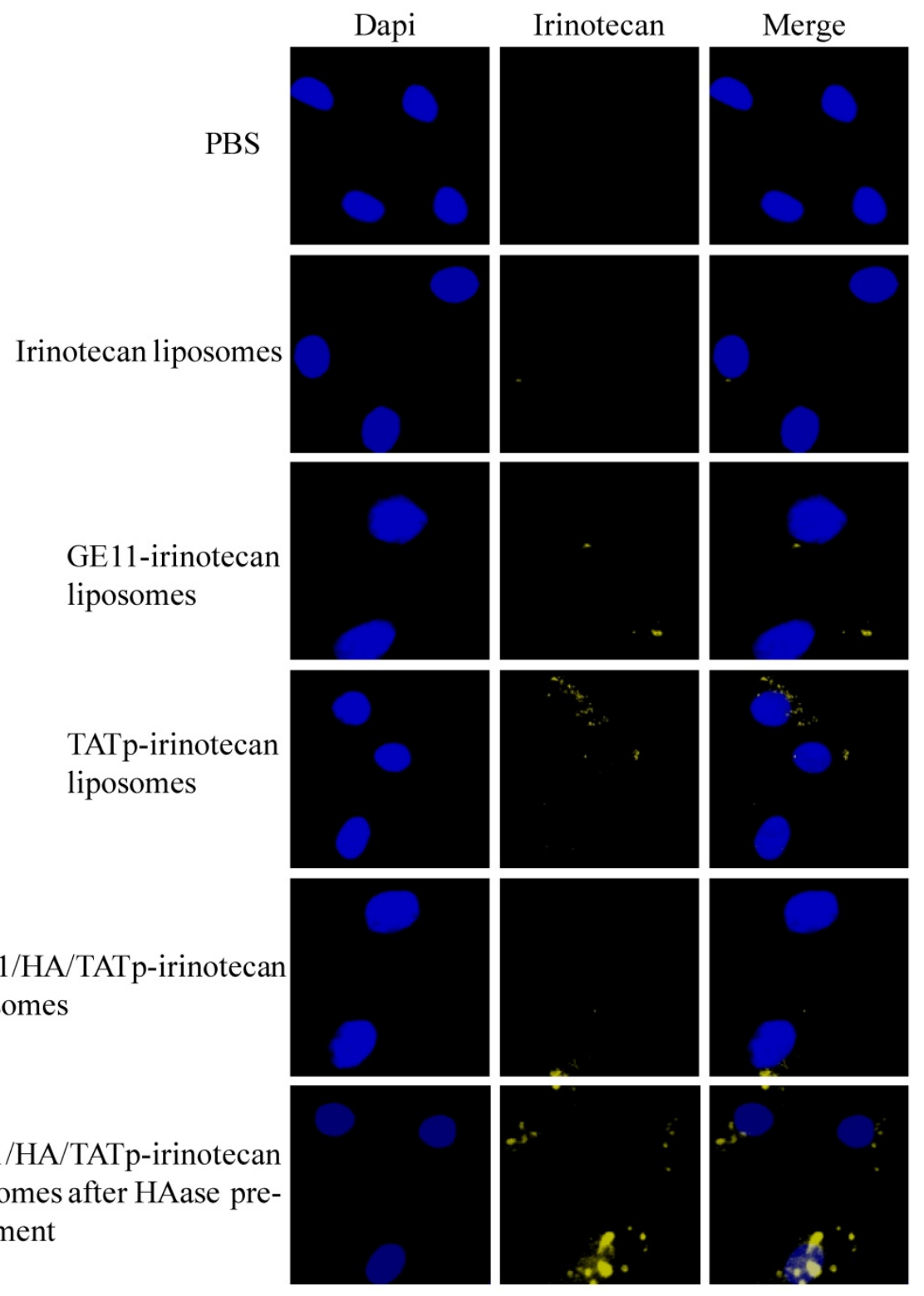

Figure 4. Drug distribution in A549 cells following applying various liposomes. Fluorescence microscopy was applied to detect irinotecan signals. Merged fluorescence images showed massive irinotecan signals (yellow) were seen in the cells treated with the GE11/HA/TATp-irinotecan liposomes after HAase pre-treatment. Note: blue, DAPI stained nuclei.

\section{Pharmacokinetics}

After administration of free irinotecan, the plasma irinotecan level dropped rapidly. While after administration of irinotecan liposomes, TATp-irinotecan liposomes, GE11-irinotecan liposomes and GE11/HA/TATp-irinotecan liposomes, the plasma irinotecan concentration decreased relatively slowly in the initial phase and remained at higher concentration levels in the terminal phase (Figure 7), resulting in longer blood exposure.

\section{Discussion}

The limitations of anticancer chemotherapy are poor solubility, non-selective activity, poor biodistri- bution and pharmacokinetics (PK), dose-limiting toxicity and also multi-drug resistance. To overcome these drawbacks, liposomes have been widely used to deliver chemotherapeutic agents because of their ability to increase drug stability, carry a large payload of drugs, improve PK and bio-distribution, enhance permeability and retention (EPR) effects in tumor tissues, reduce systemic side effect and specifically target to tumor tissues and cells by surface modification with targeting moieties including monoclonal antibodies and their fragments, peptides, proteins, aptamers, sugar moieties, and small molecules[21,22]. 
A

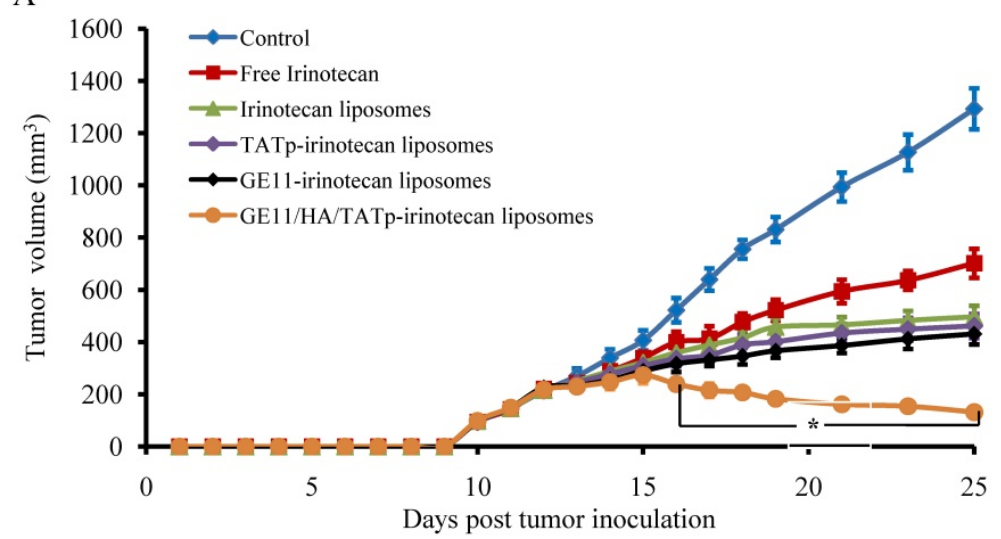

B

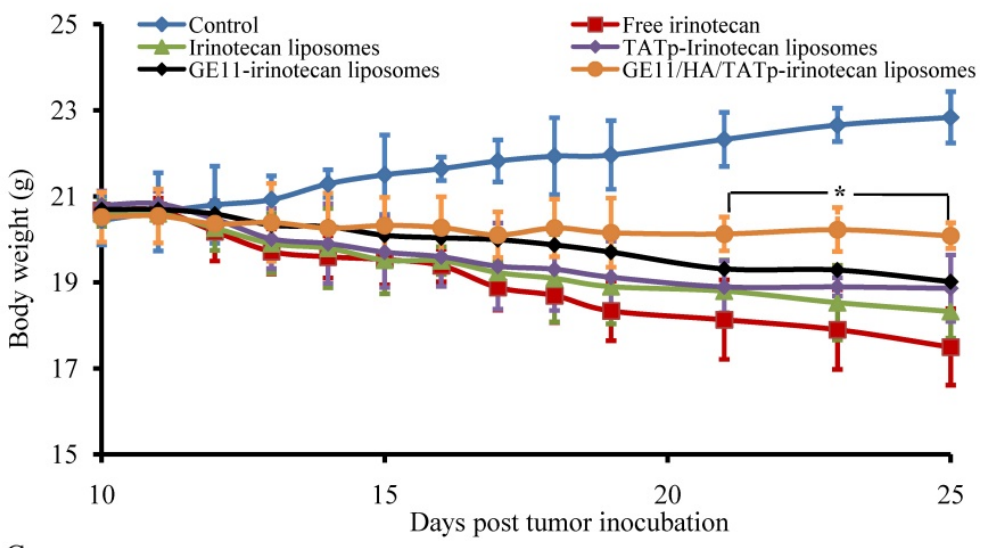

C

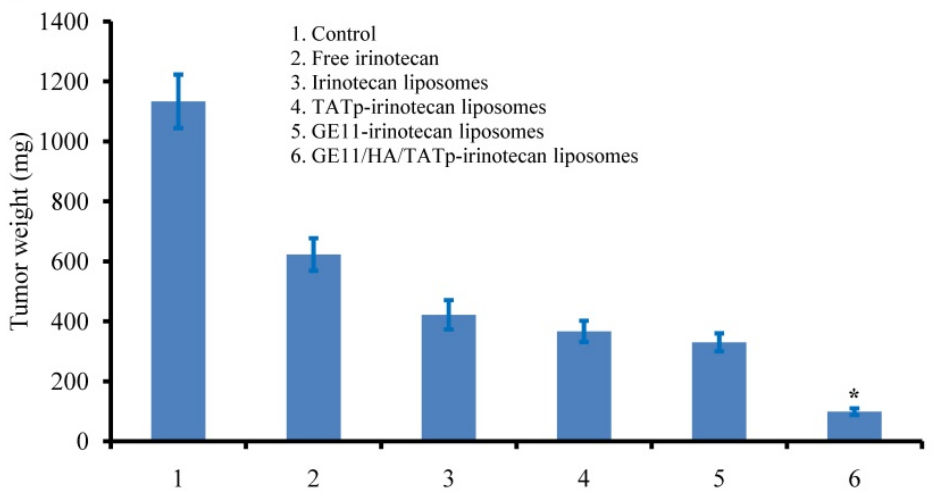

D

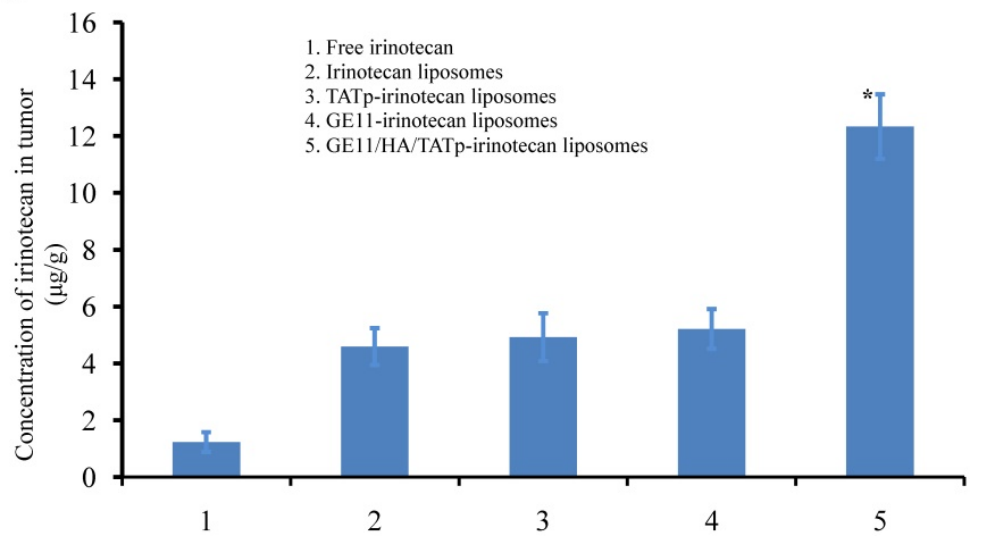

Figure 5. In vivo inhibition of the tumor growth after intravenous injection of free irinotecan and irinotecan liposomes (20.00mg/kg). (A) Antitumor activity in the A549 cells xenografts in female nude mice after treating with GE11/HA/TATp-irinotecan liposomes. (B) Body weight changes for the tumor-bearing mice after intravenous administration of various formulation.(C)Tumor weight at the 25 th day. (D) Irinotecan level in tumors at the 25 th day. Data are presented as the mean \pm SD $(n=6)$. An asterisk $(*)$ denotes a significant difference compared with the other groups $(p<0.05)$. 
A

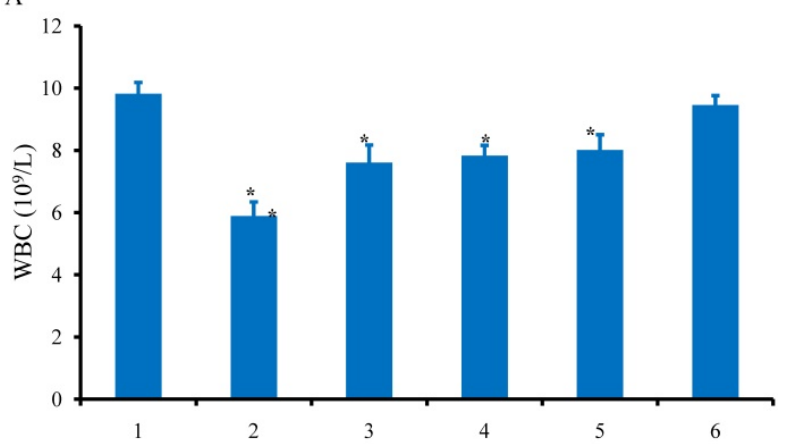

B
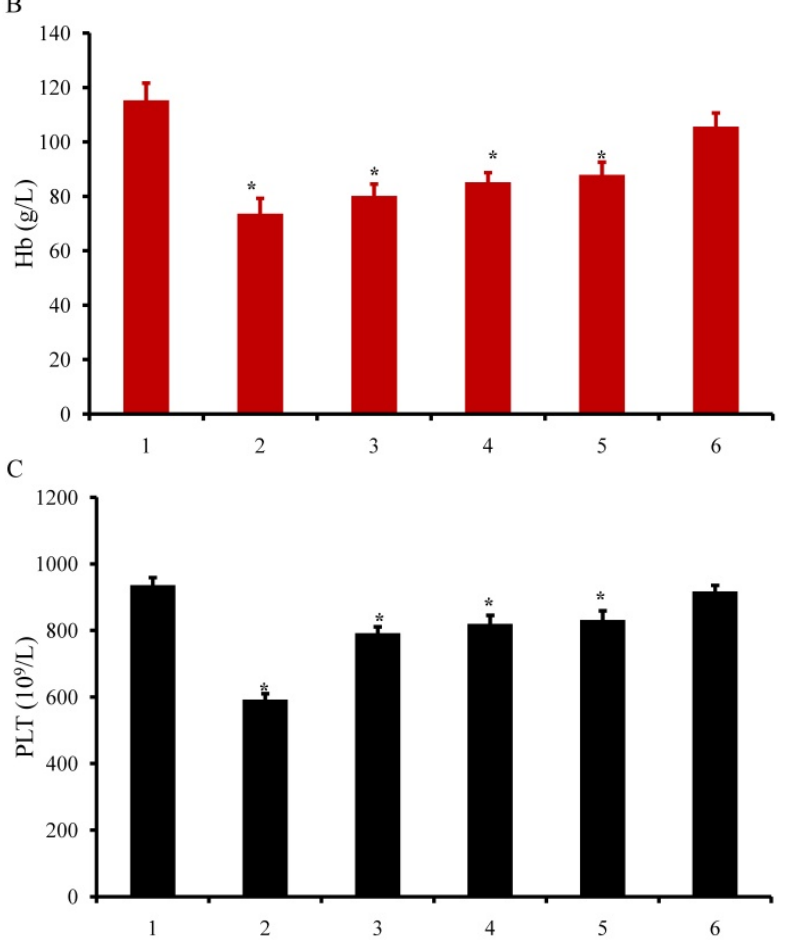

Figure 6. Activity of WBC (A), $\mathrm{Hb}(B)$ and PLT (C) as the hematological indicators of bone marrow after intravenous administration of various formulations in the A549 cells xenografts in female nude mice. Note; WBC: white blood cell; Hb: hemoglobin; PLT: platelets. Note: 1, physiological saline as control; 2, free irinotecan; 3 , irinotecan liposomes; 4, TATp-irinotecan liposomes; 5, GEl1-irinotecan liposomes; 6, GE11/HA/TATp-irinotecan liposomes. Data are presented as the mean $\pm S D(n=6)$. An asterisk $(*)$ denotes a significant difference compared with the control $(p<0.05)$.

Passive targeting of liposomes relies on the EPR effect. The EPR effect plays a crucial role in the accumulation of liposomes in tumor tissues. In order to meet the ever-increasing nutrient and oxygen demand of the growing tumor, tumor vasculature grows aberrantly which leads the endothelial cells poorly aligned with large fenestrations. This phenomena makes the tumor blood vessels highly permeable, which allows leakage of liposomes into tumor tissues and them to be retained there. This phenomenon is termed the enhanced permeation and retention (EPR) effect[23,24].

By coating the liposomal surface with PEG polymers, the tumor accumulation of liposomes can be increased due to EPR effect. PEG is effective in preventing rapid opsonization and lengthening the circulation time, which gives liposomes a better chance of extravasation through the leaky vasculature to enhance accumulation in the tumor. However, the selectivity of passive targeting based upon the EPR effect has been demonstrated to vary significantly the inherent tumor heterogeneity wherein cutoff sizes could vary between tumors. Thus, passive targeting may not suffice and active targeting may need to be utilized[25,26].

Functionalization of liposomes for active targeting by chemically modifying their surface with targeting ligands show a strong specificity for antigens or receptors over-expressed on cancer cells. The targeting ligands can be attached to the termini of PEG chain and the anti-tumoral efficacy is enhanced by cellular internalization rather than just an increased tumor accumulation by receptor-mediated endocytosis $[27,28]$.

A wide variety of targeting molecules have been investigated to date for active targeting of liposomes. An added sophistication to active targeting of liposomes can be brought about by utilizing certain stimuli in tumor microenvironment including low $\mathrm{pH}$, redox status of the cell, and the presence of certain over-expressed enzymes. The $\mathrm{pH}$-sensitive liposomes are parpared by incorporation of $\mathrm{pH}$-sensitive fusogenic peptides either derived from viruses (like haemagglutinin, gp41, and diINF-7), bacteria (such as listeriolysin $\mathrm{O}$ and diphtheria toxin), plants (ricin, saporin, and gelonin) or by enriching with $\mathrm{pH}$-sensitive polymers such as $\mathrm{N}$-isopropylacrylamide, poly(glycidol)s, or poly(alkyl acrylic acid)s. About the enzyme-responsive liposomes, the most-common examples of certain over-expressed enzymes are Secreted phospholipase $\mathrm{A}_{2} \quad\left(\mathrm{sPLA}_{2}\right)$, Matrix metalloproteinases (MMPs), urokinase plasminogen activator (uPA), elastase, prostate-specific antigen (PSA), cathepsin B and so on. Different strategies have been developed for liposomal agents release by utilizing the stimuli of enzymes. Enzyme-sensitive liposomes, which respond to stimuli of enzyme for "triggered" release to achieve temporal and spatial control over the release of therapeutic payloads, take advantage of the over-expression of certain enzymes in cancer to cause structural changes of liposomes by the enzymatic reaction[29,30]. Liposomes of light activation and heat activation have also been used to enhance the delivery of irinotecan[31, 32].

In this study, HAase-sensitive dual-targeting irinotecan liposomes were developed for the treatment of lung cancer. The flexible long PEG chains were used to prolong circulation time in the blood and the over-expressed HAase was used as a stimulus 


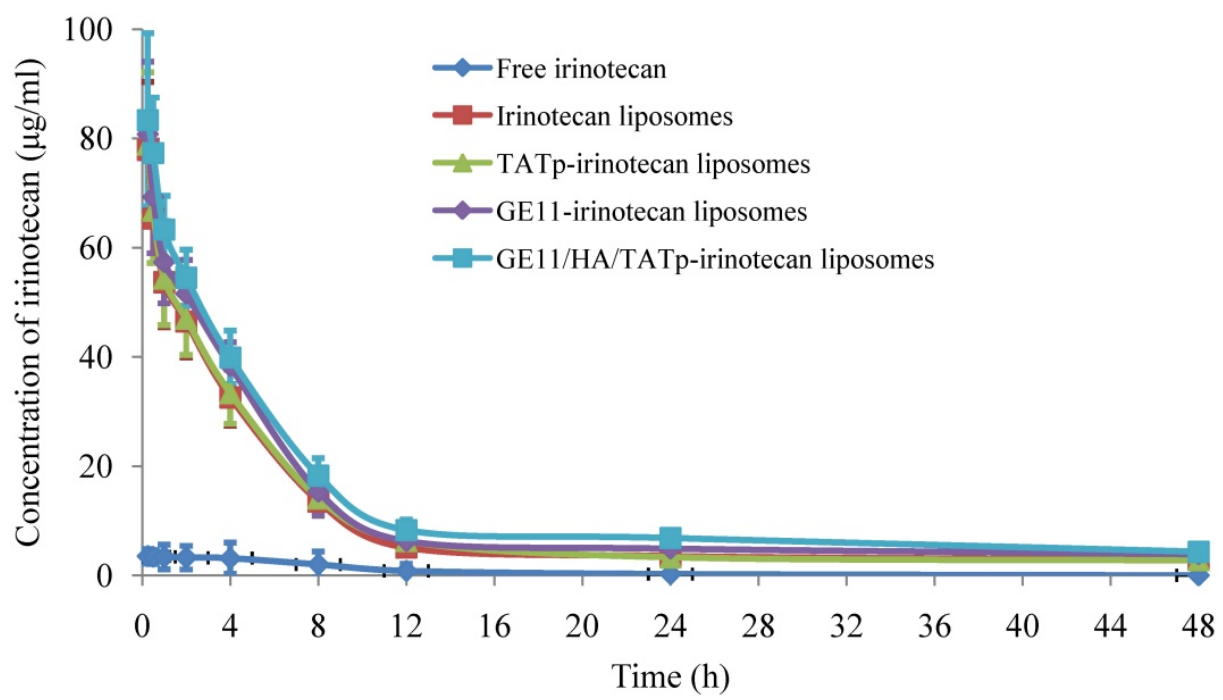

Figure 7. Time course of irinotecan levels in plasma after intravenous administration of free irinotecan $(20.00 \mathrm{mg} / \mathrm{kg})$, irinotecan liposomes $(20.00 \mathrm{mg} / \mathrm{kg})$, TATp-irinotecan liposomes $(20.00 \mathrm{mg} / \mathrm{kg})$, GE1 1-irinotecan liposomes $(20.00 \mathrm{mg} / \mathrm{kg})$ and GE1 1/HA/TATp-irinotecan liposomes $(20.00 \mathrm{mg} / \mathrm{kg})$. Each point represents means \pm SD $(\mathrm{n}=6)$.

to trigger the enhanced tumor targeting in our newly designed liposomes. First of all, the GE11 was used to allow for the specific targeting of A549 lung cancer cells. Then, HA between PEG and lipid was degraded in the tumor tissues by the up-regulated extracellular HAase for the removal of PEG chains. Finally, after long-chain PEG removal and exposure of the previously hidden surface-attached cell-penetrating peptide (TATp), TATp triggered the endocytosis, which exhibited a significantly higher uptake (Figure $1 \mathrm{~A}$ and $\mathrm{B})$.

Results demonstrate that GE11/HA/TATpirinotecan liposomes have the following physicochemical features: high encapsulation efficiency (Table 1), well-distributed particle size (Figure 2A), and delayed drug release (Figure 2B). The particle size of liposomes is approximated 50nm, which allows them to circulate in the blood for extended periods by evading the mononuclear phagocytic system (MPS) in the liver. And their size is large enough to prevent fast renal clearance. Tumor vasculature cut off sizes can vary between tumors and the size has a crucial role in the accumulation of liposomes. The small sized liposomes are well below the cutoff limit for most tumors for entering tumor tissues. A lower drug release will be beneficial for preventing the rapid leakage during the process of delivery and blood circulation, thereby possibly increasing the accumulation of irinotecan into the tumor masses.

Cytotoxicity results demonstrate that the GE11/HA/TATp-irinotecan liposomes exhibit strong inhibitory effect to A549 lung cancer cells after HAase pre-treatment (Figure 2C). The enhanced inhibitory effects are explained by A549 lung cancer cells uptake study by fluorescence microscope in which the GE11/HA/TATp-irinotecan liposomes are the most strongly endocytosed by A549 lung cancer cells. In good agreement with our cytotoxicity studies, robust fluorescence signals of irinotecan were detected in cytoplasm of the A549 lung cancer cells incubated with GE11/HA/TATp-irinotecan liposomes after HAase pre-treatment, indicating the specificity of GE11/HA/TATp-irinotecan liposomes (Figure 3).

The inhibitory effects on tumor volume in the A549 lung cancer cells xenografted female nude mice demonstrate that, by intravenous injection administration, the GE11/HA/TATp-irinotecan liposomes exhibit significantly higher antitumor activity as compared to TATp-irinotecan liposomes, GE11-irinotecan liposomes, irinotecan liposomes and free irinotecan (Figure $4 \mathrm{~A}$ and $\mathrm{C}$ ). As compared to TATp-irinotecan liposomes, GE11-irinotecan liposomes, irinotecan liposomes and free irinotecan, GE11/HA/TATp-irinotecan liposomes do not cause an appreciable reduction in body weight (Figure 4B).

After administering GE11/HA/TATp-irinotecan liposomes to the A549 lung cancer cells xenografted female nude mice, the bone marrow indicators (WBC, $\mathrm{Hb}$, and PLT) are mildly decreased, suggesting that GE11/HA/TATp-irinotecan liposomes may have no significant influences on bone marrow (Figure 5). At least, the potential myelosuppression effect may be no more than those after administering free irinotecan, irinotecan liposomes, GE11-irinotecan liposomes and TATp-irinotecan liposomes. Gastrointestinal toxicity (diarrhea) is frequent observed after administration of free irinotecan. It was controlled with the administration of GE11/HA/TATp-irinotecan liposomes, TATp-irinotecan liposomes, GE11-irinotecan liposomes and irinotecan liposomes. Furthermore, GE11/HA/TATp-irinotecan liposomes demonstrate a robust anticancer activity against the tumor xenografted with A549 lung cancer cells. 
The HAase-sensitive dual-targeting irinotecan liposomes have been successfully developed and evaluated in vitro and in vivo, but the translation from basic to clinical research is very limited. The complex preparation process, sophisticated production equipment, and difficulties in scale up synthesis of such "smart" nanoplatforms make the translation of liposomes from experimental study to clinical application tedious and cost-ineffective. In addition, the efficacy of such "smart" nanoplatforms may be different from one patient to another due to different levels of enzyme at the targeting tumor tissue. Therefore, future research needs to focus on the feasibility and practicality of this novel formulation in clinical treatment.

\section{Conclusions}

In the current work, we have successfully synthesized the novel functional polymers and developed a novel HAase-sensitive dual-targeting irinotecan liposomes with high entrapped efficiency, perfect size distribution, and slow releasing. This kind of liposomes specifically target lung cancer cells, respond to the up-regulated extracellular HAase in tumors microenvironment, and provide enhanced cellular internalization via a cell penetration function (TATp), resulting in enhancing the concentration of irinotecan in tumors and exhibiting strong inhibitory effect to lung tumor volume. Thus, the present study provides a new strategy for treatment of the lung cancer.

\section{Acknowledgments}

This work was supported in part by the Agricultural Science and Technology Innovation Program and the Major National Scientific Research Program of China (973 Program, 2014CB932200).

\section{Competing Interests}

The authors have declared that no competing interest exists.

\section{References}

1. Du W, Xu X, Niu Q, Zhang X, Wei Y, Wang Z, et al. Spi-B-Mediated Silencing of Claudin-2 Promotes Early Dissemination of Lung Cancer Cells from Primary Tumors. Cancer Res. 2017; 77:4809-4822.

2. Tan L, Peng J, Zhao Q, Zhang L, Tang X, Chen L, et al. A Novel MPEG-PDLLA-PLL Copolymer for Docetaxel Delivery in Breast Cancer Therapy. Theranostics. 2017; 7:2652-2672.

3. Mikhaylov G, Mikac U, Magaeva AA, Itin VI, Naiden EP, Psakhye I, et al. Ferri-liposomes as an MRI-visible drug-delivery system for targeting tumours and their microenvironment. Nat Nanotechnol. 2011; 6:594-602.

4. Felfoul O, Mohammadi M, Taherkhani S, de Lanauze D, Zhong Xu Y, Loghin D, et al. Magneto-aerotactic bacteria deliver drug-containing nanoliposomes to tumour hypoxic regions. Nat Nanotechnol. 2016; 11:941-947.

5. Lin G, Mi P, Chu C, Zhang J, Liu G. Inorganic Nanocarriers Overcoming Multidrug Resistance for Cancer Theranostics. Adv Sci (Weinh). 2016; 3:1600134.
6. Jiang TY, Mo R, Bellotti A, Zhou JP, Gu Z. Gel-Liposome-Mediated Co-Delivery of Anticancer Membrane-Associated Proteins and Small-Molecule Drugs for Enhanced Therapeutic Efficacy. Adv Mater. 2014; 24: 2295-2304

7. Colzani B, Speranza G, Dorati R, Conti B, Modena T, Bruni G, et al. Design of smart GE11-PLGA/PEG-PLGA blend nanoparticulate platforms for parenteral administration of hydrophilic macromolecular drugs: synthesis, preparation and in vitro/ex vivo characterization. Int J Pharm. 2016; 511:1112-23.

8. Cheng L, Huang FZ, Cheng LF, Zhu YQ, Hu Q, Li L, et al. GE11-modified liposomes for non-small cell lung cancer targeting: preparation, ex vitro and in vivo evaluation. Int J Nanomedicine. 2014; 9:921-35.

9. Zhu L, Kate P, Torchilin VP. Matrix metalloprotease 2-responsive multifunctional liposomal nanocarrier for enhanced tumor targeting. ACS Nano. 2012; 6:3491-8.

10. Pappalardo JS, Langellotti CA, Di Giacomo S, Olivera V, Quattrocchi V, Zamorano PI, et al. In vitro transfection of bone marrow-derived dendritic cells with TATp-liposomes. Int J Nanomedicine. 2014; 9:963-73.

11. Zhong Y, Zhang J, Cheng R, Deng C, Meng F, Xie F, et al. Reversibly crosslinked hyaluronic acid nanoparticles for active targeting and intelligent delivery of doxorubicin to drug resistant CD44+ human breast tumor xenografts. J Control Release. 2015; 205:144-54.

12. Zhong Y, Goltsche K, Cheng L, Xie F, Meng F, Deng C, et al. Hyaluronic acid-shelled acid-activatable paclitaxel prodrug micelles effectively target and treat CD44-overexpressing human breast tumor xenografts in vivo. Biomaterials. 2016; 84:250-61.

13. Béduneau A, Saulnier P, Hindré F, Clavreul A, Leroux JC, Benoit JP. Design of targeted lipid nanocapsules by conjugation of whole antibodies and antibody Fab' fragments. Biomaterials. 2007; 28:4978-90.

14. Kaldybekov DB, Tonglairoum P, Opanasopit P, Khutoryanskiy VV. Mucoadhesive maleimide-functionalised liposomes for drug delivery to urinary bladder. Eur J Pharm Sci. 2018;111:83-90.

15. Chen KJ, Chaung EY, Wey SP, Lin KJ, Cheng F, Lin CC, et al. Hyperthermia-mediated local drug delivery by a bubble-generating liposomal system for tumor-specific chemotherapy. ACS Nano. 2014; 8:5105-15.

16. Song S, Liu D, Peng J, Sun Y, Li Z, Gu JR, et al. Peptide ligand-mediated liposome distribution and targeting to EGFR expressing tumor in vivo. Int J Pharm. 2008; 363:155-61.

17. Gazzano E, Rolando B, Chegaev K, Salaroglio IC, Kopecka J, Pedrini I, et al. Folate-targeted liposomal nitrooxy-doxorubicin: An effective tool against P-glycoprotein-positive and folate receptor-positive tumors. J Control Release. 2018; 270:37-52.

18. Shaji J, Menon I. PEGylated Liposomes of Meloxicam: Optimization by Quality by Design, in vitro Characterization and Cytotoxicity Evaluation. Pharm Nanotechnol. 2017; 5:119-137.

19. Wang $Y$, Lin $T$, Zhang W, Jiang $Y$, Jin H, He H, et al. A Prodrug-type, MMP-2-targeting Nanoprobe for Tumor Detection and Imaging. Theranostics. 2015; 5:787-95.

20. Gou M, Men K, Shi H, Xiang M, Zhang J, Song J, et al. Curcumin-loaded biodegradable polymeric micelles for colon cancer therapy in vitro and in vivo. Nanoscale. 2011; 3:1558-67.

21. Alibakhshi A, Abarghooi Kahaki F, Ahangarzadeh S, Yaghoobi H, Yarian F, Arezumand R, et al. Targeted cancer therapy through antibody fragments-decorated nanomedicines. J Control Release. 2017; 268:323-334.

22. Blocker SJ, Douglas KA, Polin LA, Lee H, Hendriks BS, Lalo E, et al. Liposomal 64Cu-PET Imaging of Anti-VEGF Drug Effects on Liposomal Delivery to Colon Cancer Xenografts. Theranostics. 2017; 7:4229-4239.

23. Jo J, Lee $\mathrm{CH}$, Kopelman $\mathrm{R}$, Wang $\mathrm{X}$. In vivo quantitative imaging of tumor $\mathrm{pH}$ by nanosonophore assisted multispectral photoacoustic imaging. Nat Commun. 2017; 8:471

24. Stefanick JF, Ashley JD, Kiziltepe T, Bilgicer B. A systematic analysis of peptide linker length and liposomal polyethylene glycol coating on cellular uptake of peptide-targeted liposomes. ACS Nano. 2013; 7:2935-47.

25. Song $\mathrm{H}, \mathrm{Su} \mathrm{X}$, Yang $\mathrm{K}$, Niu F, Li J, Song J, et al. CD20 Antibody-Conjugated Immunoliposomes for Targeted Chemotherapy of Melanoma Cancer Initiating Cells. J Biomed Nanotechnol. 2015; 11:1927-46.

26. Chertok B, Langer R, Anderson DG. Spatial Control of Gene Expression by Nanocarriers Using Heparin Masking and Ultrasound-Targeted Microbubble Destruction. ACS Nano. 2016; 10:7267-78.

27. Chi Y, Yin X, Sun K, Feng S, Liu J, Chen D, et al. Redox-sensitive and hyaluronic acid functionalized liposomes for cytoplasmic drug delivery to osteosarcoma in animal models. J Control Release. 2017; 261:113-125.

28. Belhadj Z, Ying M, Cao X, Hu X, Zhan C, Wei X, et al. Design of $Y$-shaped targeting material for liposome-based multifunctional 
glioblastoma-targeted drug delivery. J Control Release. 2017; 255:132-141.

29. Zhang L, Cao DY, Wang J, Xiang B, Dun JN, Fang Y, et al. PEG-coated irinotecan cationic liposomes improve the therapeutic efficacy of breast cancer in animals. Eur Rev Med Pharmacol Sci. 2013; 17:3347-61.

30. Scomparin A, Florindo HF, Tiram G, Ferguson EL, Satchi-Fainaro R. Two-step polymer- and liposome-enzyme prodrug therapies for cancer: PDEPT and PELT concepts and future perspectives. Adv Drug Deliv Rev. 2017; 118:52-64.

31. Carter KA, Luo D, Razi A, Geng J, Shao S, Ortega J, et al. Sphingomyelin Liposomes Containing Porphyrin-phospholipid for Irinotecan Chemophototherapy. Theranostics. 2016; 6:2329-2336.

32. Casadó A, Sagristá ML, Mora M. Formulation and in vitro characterization of thermosensitive liposomes for the delivery of irinotecan. J Pharm Sci. 2014 ;103:3127-38 